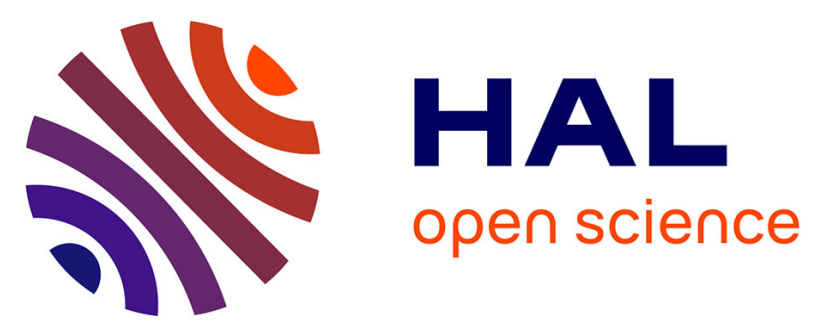

\title{
Incorporation of a platinum center in the pi-conjugated core of push-pull chromophores for nonlinear optics (NLO)
}

\author{
Raphaël Durand, Sébastien Gauthier, Sylvain Achelle, Samia Kahlal, \\ Jean-Yves Saillard, Alberto Barsella, Laurianne Wojcik, Nicolas Le Poul, \\ Francoise Robin-Le Guen
}

\section{To cite this version:}

Raphaël Durand, Sébastien Gauthier, Sylvain Achelle, Samia Kahlal, Jean-Yves Saillard, et al.. Incorporation of a platinum center in the pi-conjugated core of push-pull chromophores for nonlinear optics (NLO). Dalton Transactions, 2017, 46 (9), pp.3059-3069. 10.1039/c7dt00252a . hal-01500397

\section{HAL Id: hal-01500397}

\section{https://hal-univ-rennes1.archives-ouvertes.fr/hal-01500397}

Submitted on 17 Jul 2017

HAL is a multi-disciplinary open access archive for the deposit and dissemination of scientific research documents, whether they are published or not. The documents may come from teaching and research institutions in France or abroad, or from public or private research centers.
L'archive ouverte pluridisciplinaire HAL, est destinée au dépôt et à la diffusion de documents scientifiques de niveau recherche, publiés ou non, émanant des établissements d'enseignement et de recherche français ou étrangers, des laboratoires publics ou privés. 


\section{Incorporation of a platinum center in pi-conjugated core of push-pull chromophores for Nonlinear Optics (NLO).}

Raphaël J. Durand, ${ }^{\text {a }}$ Sébastien Gauthier, ${ }^{\text {aa }}$ Sylvain Achelle, ${ }^{\text {*a }}$ Samia Kahlal, ${ }^{\text {b Jean-Yves }}$ Saillard, ${ }^{\mathrm{b}}$ Alberto Barsella, ${ }^{\mathrm{c}}$ Laurianne Wojcik, ${ }^{\mathrm{d}}$ Nicolas Le Poul, ${ }^{\mathrm{d}}$ and Françoise Robin-Le Guen $^{\mathrm{a}}$

${ }^{a}$ Institut des Sciences Chimiques de Rennes, UMR CNRS 6226, IUT de Lannion, rue Edouard Branly, BP 30219, F-22302 Lannion Cedex, France. E-mails: sebastien.gauthier@univ-rennes1.fr, sylvain.achelle@univ-rennes1.fr Tel:+33296469344, +33296469448

${ }^{\mathrm{b}}$ Institut des Sciences Chimiques de Rennes, UMR CNRS 6226, Campus de Beaulieu, 263 av. Général Leclerc, 35042 Rennes, France.

${ }^{\mathrm{c}}$ Département d'Optique ultra-rapide et Nanophotonique, IPCMS-CNRS, 23 rue du Loess, BP 43, 67034 Strasbourg Cedex 2, France.

${ }^{d}$ Laboratoire de Chimie, Électrochimie Moléculaires et Chimie Analytique, UMR CNRS 6521, Université de Bretagne Occidentale, UFR Sciences et Techniques, 6 avenue Victor Le Gorgeu - CS 93837, F-29238 Brest Cedex 3, France

\section{Abstract}

In this article, we describe the synthesis, redox characteristics, linear and nonlinear optical (NLO) properties of seven new unsymmetrical push-pull diacetylide platinum-based complexes. These $\mathrm{D}-\pi-\mathrm{Pt}-\pi$-A complexes incorporate pyranylidene ligands as pro-aromatic donor groups (D), diazine rings as electron-withdrawing groups (A), and various aromatic fragments (styryl or thienylvinyl) as $\pi$-linkers separating the platinum diacetylide unit from the donor and the acceptor groups. This is one of the first examples of push-pull chromophores incorporating a platinum center in the $\pi$-conjugated core. The NLO properties of these complexes were compared with those of their purely organic analogues. All compounds (organic and organometallic) exhibited positive $\mu \beta$ values, which dramatically increased upon methylation of the pyrimidine fragment. However, this increase was even more significant in the complexes due to the presence of platinum in the $\pi$-conjugated core. 
The effects of the linker on the redox and spectroscopic properties of the complexes are also discussed. In addition, DFT calculations were performed in order to gain further insight into the intramolecular charge transfer (ICT) occurring through the platinum center.

Key words: Pyranylidene; Diazine; Platinum Complexes; Nonlinear Optics; Intramolecular Charge Transfer

\section{Introduction}

Due to their applications in a wide range of photonic $^{1}$ and optoelectronic devices, ${ }^{2}$ molecular systems displaying second order nonlinear optical (NLO) properties have been subject to intensive research during the past two decades. For example, second-order NLO materials have found applications in blue/green laser obtained from red sources through frequency doubling, in second-harmonic generation or terahertz wave generation. ${ }^{3}$ The typical design of second-order NLO chromophores, also called linear push-pull design, is based on a conjugated $\pi$-electron system asymmetrically substituted by an electron-donor (D) group and an electron acceptor (A). In such molecular system, efficient intramolecular charge transfer (ICT) occurs from the donor to the acceptor leading to the polarization of the molecule. The ICT can easily be illustrated by two limiting resonance forms (neutral and zwitterionic form). ${ }^{4}$ The NLO response is maximum when the contribution of the two forms is optimized. In pushpull molecules, ICT can easily be tuned by varying various parameters: the nature of the donor/acceptor couple and the $\pi$-conjugated spacer. $^{5}$ Microscopically, second-order NLO response of chromophores can be represented by the scalar product of the vector part of the hyperpolarizability tensor $(\beta)$ and the dipole moment $(\mu)$ measured by the electric-field induced second hamormic (EFISH) technique. ${ }^{4 b}$ 
Diazines are six-membered heterocycles with two nitrogen atoms. Due to their $\pi$-deficient character, diazinyl fragments such as pyrimidyl groups, can be used as electron-withdrawing group in push-pull structures. ${ }^{6}$ Numerous diazine-based chromophores exhibiting ICT have been described, ${ }^{7}$ and 4,6-di(arylvinyl)pyrimidine chromophores have become well-established two-photon absorption (TPA) dyes. ${ }^{8}$ While 4 -aminostyrylpyrimidine chromophores exhibit relatively moderate second-order NLO responses, ${ }^{9}$ extension of the $\pi$-conjugated scaffold ${ }^{10}$ as well as complexation or the methylation of the pyrimidine ring ${ }^{11}$ in such structures result in a significant increase of the $\mu \beta$ values.

Another way to increase the ICT is through the incorporation of proaromatic moieties capable of gaining aromaticity upon ICT process into the push-pull structure. ${ }^{12}$ This is the case of $\gamma$ pyranylidene fragments, which upon ICT, gain a pyrylium aromatic character. This moiety has efficiently been used as an electron-donating group is the push-pull structures of secondorder NLO dyes ${ }^{13}$ and chromophores for dye-sensitized solar cells (DSSC). ${ }^{14}$ It has recently been shown that the NLO responses of pyranylidene-substituted styryl pyrimidine derivatives are significantly higher than those of their amino analogues. ${ }^{15}$ The donor capacity of pyranylidene fragments is also exemplified by the chemical or electrochemical oxidation of the methylenepyran moiety leading to a radical cation, which dimerizes to bispyrylium and extended bispyran. ${ }^{16}$

Metal $\sigma$-acetylide fragments have been incorporated in the structure of NLO chromophores making some of them amongst the most efficient organic or inorganic quadratic NLO-phores thus far. ${ }^{17}$ The almost linear $\mathrm{M}-\mathrm{C} \equiv \mathrm{C}-\mathrm{R}$ structure allows for a suitable coupling between the $\mathrm{d}$ orbitals of the metal and the $\pi^{*}$ system of the $\sigma$-acetylide bridge leading to an effective charge transfer. ${ }^{18}$ These fragments are generally used as electron donors in the push-pull structures. ${ }^{19}$ Linear neutral platinum bisacetylide segments can also be used as linkers in chromophore structures. ${ }^{20}$ These segments 
generally consist of D- $\pi$-Pt- $\pi$-D structures for two-photon absorption (TPA), in which the metal center increases the conjugation length. ${ }^{21}$ Asymmetrical D- $\pi$-Pt- $\pi$-A structures are less common. ${ }^{22}$ It has been shown, however, that platinum bis-acetylide complexes exhibit $\beta$ values slightly higher than those their organic analogues. ${ }^{22 a}$ Recently, some of us have described such compounds as chromophores for DSSC. ${ }^{23}$

In this contribution, we describe the synthesis, electrochemical, photophysical and second order NLO properties of a new series of seven platinum complexes D- $\pi$-Pt- $\pi$-A (1-7) that associate pyranylidene electron-donating groups and diazine electron-withdrawing groups separated by a platinum bis-acetylide fragment and $\pi$-conjugated linkers (Chart 1 ). The properties of some of them are compared with their purely organic analogues (8-11) (Chart 2) and structure-property relationships are established. 


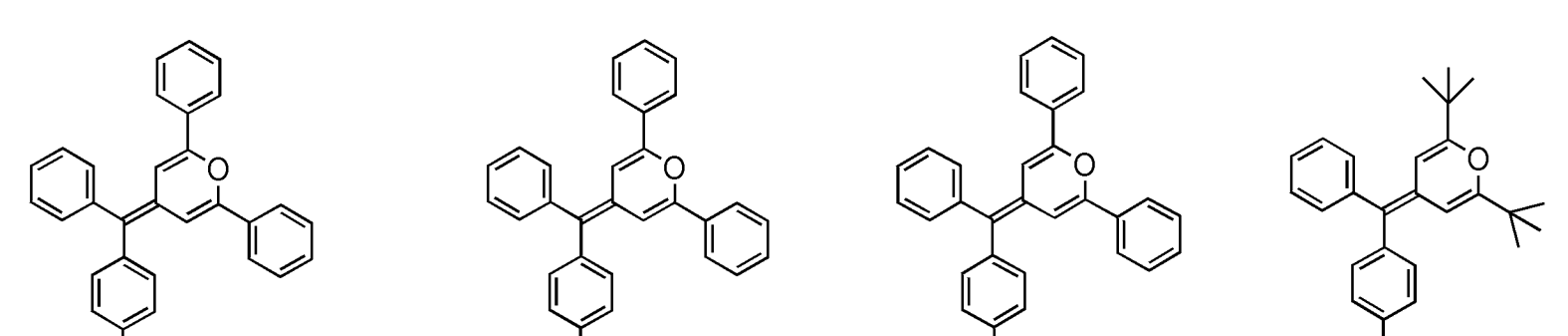

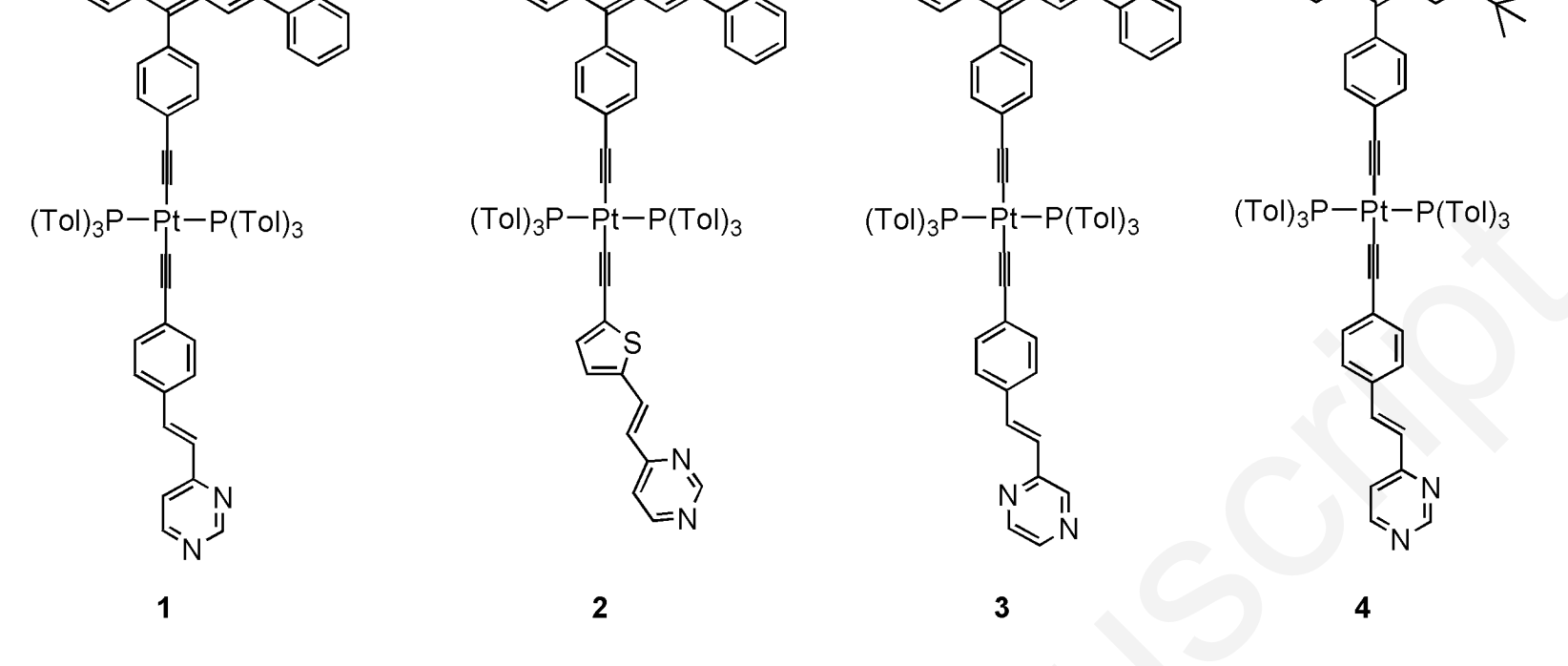

ox aco acto

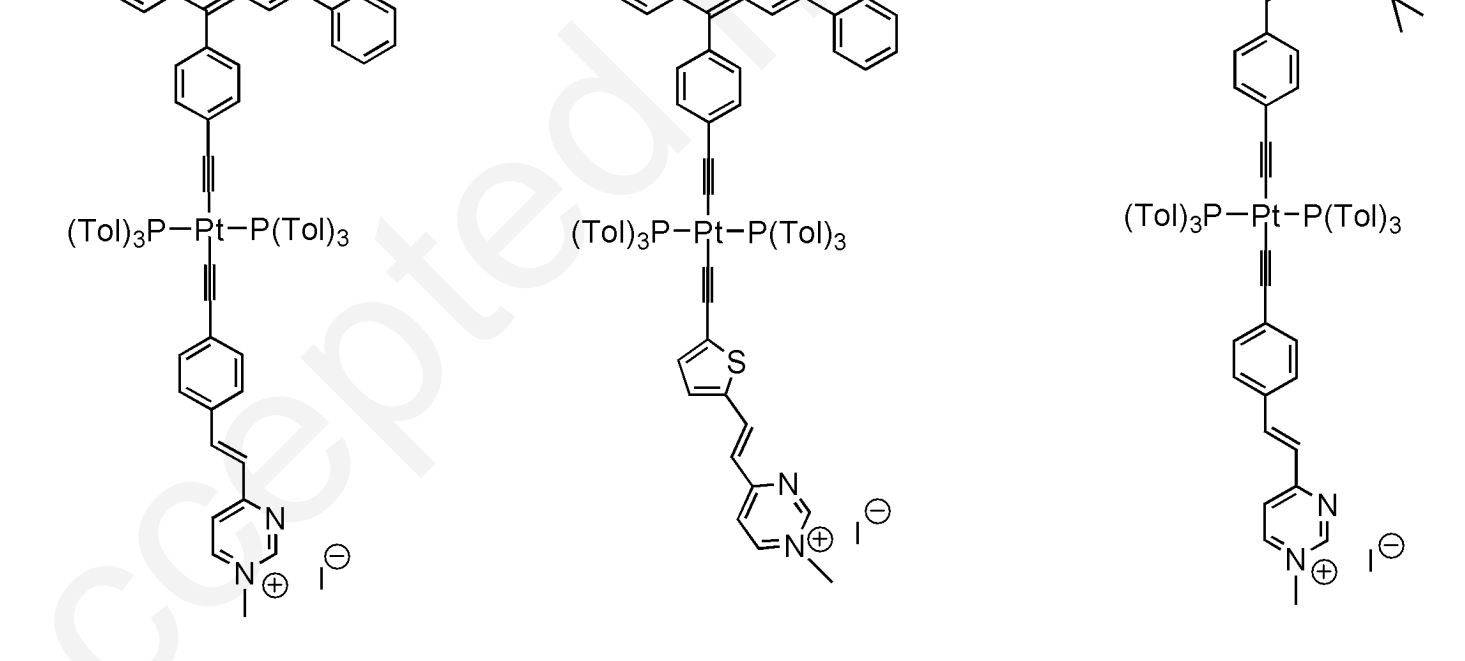



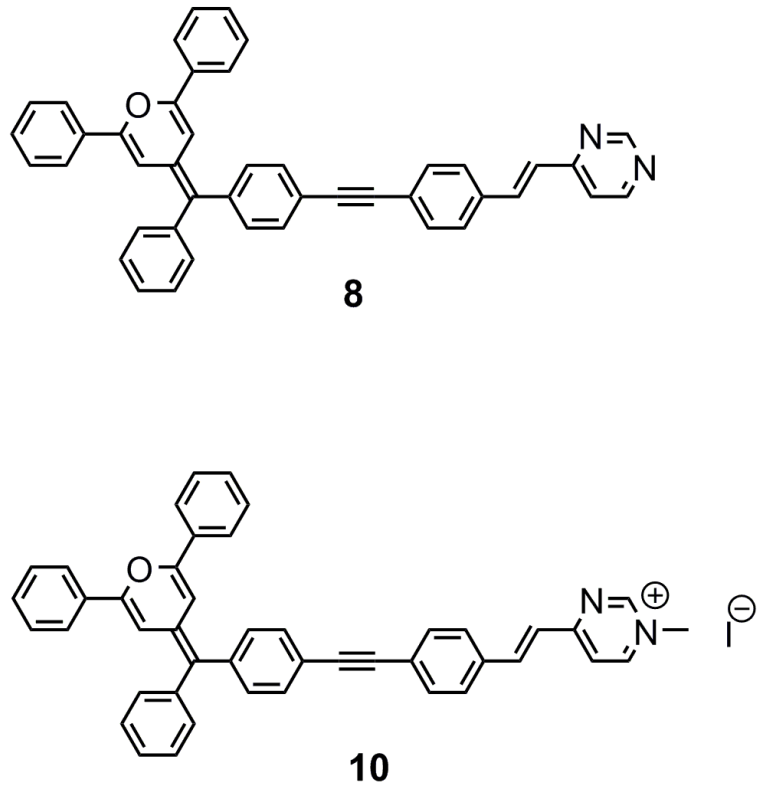
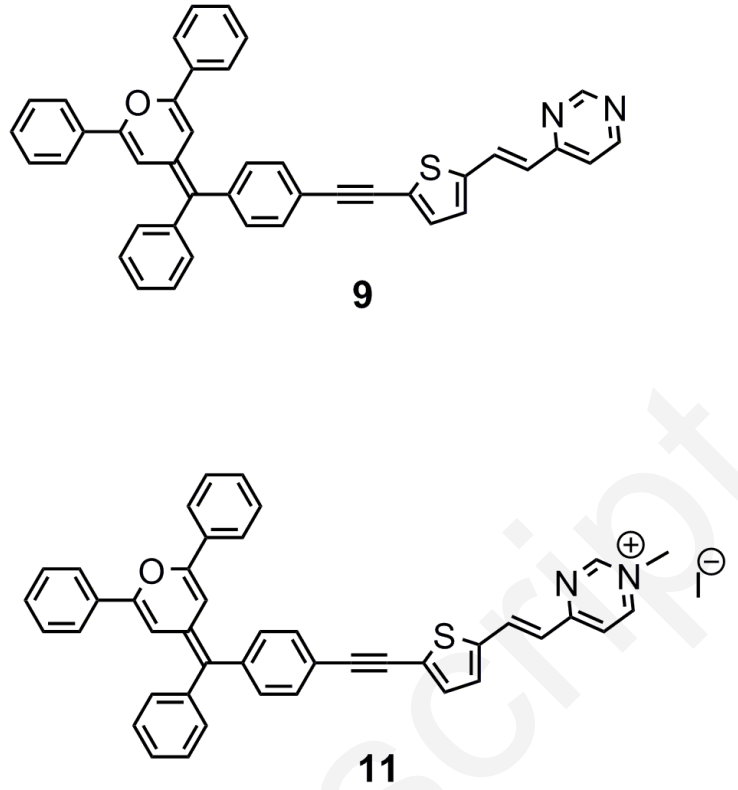

\section{Chart 2.}

\section{Results and discussion}

\section{Synthesis of the chromophores}

The synthetic approach to unsymmetrical platinum-diacetylide complexes $\mathbf{1 - 7}$, depicted in Scheme 1, was based upon a well-documented procedure. ${ }^{24}$ The first step consists of the formation of the precursor complexes 14-15 from pyranylidene derivatives $\mathbf{1 2}^{-13}{ }^{23}$ by reaction with cis- $\left[\mathrm{Pt}\left(\mathrm{P}(\mathrm{Tol})_{3}\right)_{2} \mathrm{Cl}_{2}\right]$ in the presence of a catalytic amount of copper(I) iodide and diethylamine at $60{ }^{\circ} \mathrm{C}$. In this reaction, an excess of cis- $\left[\mathrm{Pt}\left(\mathrm{P}(\mathrm{Tol})_{3}\right)_{2} \mathrm{Cl}_{2}\right]$ was necessary to minimize the formation of undesirable oligomeric byproducts. ${ }^{25}$ Subsequent coupling with the corresponding diazine derivatives $\mathbf{1 6 - 1 8}{ }^{10}$ under conventional cross-coupling conditions resulted in compounds 1-4 (Scheme 1). The $N$-methylation of complexes 5-7 was carried out with iodomethane under reflux without solvent. As described in the literature, $N$-methylation occured regioselectively on the diazine rings and methylated derivatives 5-7 were obtained in good yields (Scheme 2). ${ }^{26}$ 


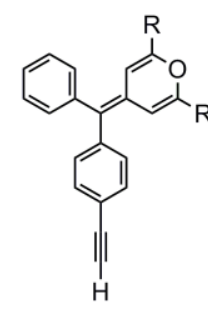

$12, R=P h$

$13, R=t B u$
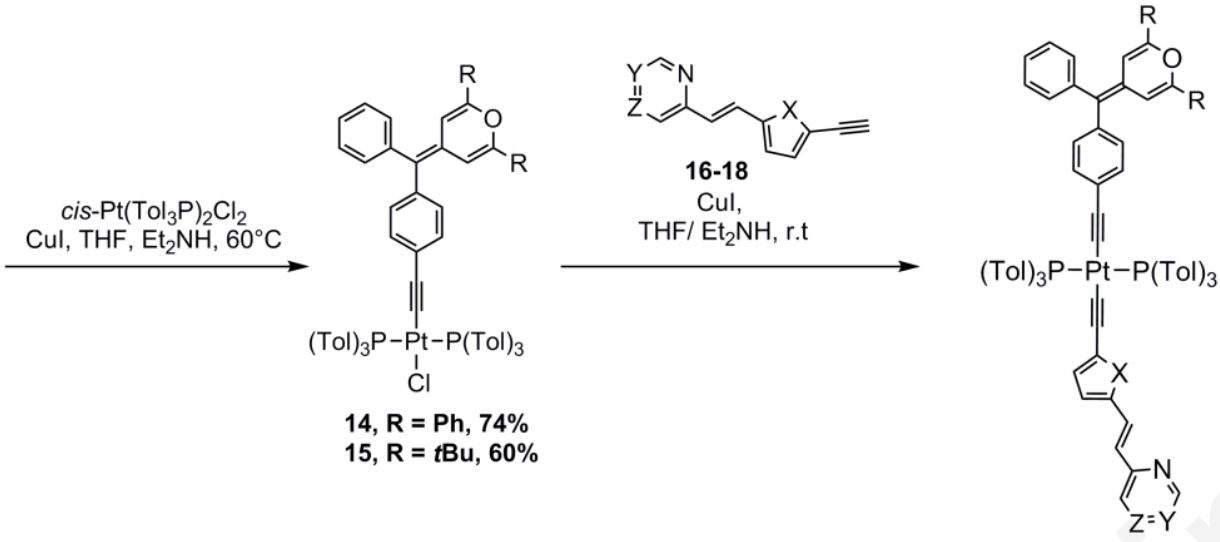

$1, R=P h, X: C=C, Y=N, Z=C, 59 \%$

2, $R=P h, X: S, Y=N, Z=C, 86 \%$

3, $R=P h, X: C=C, Y=C, Z=N, 65 \%$

$4, R=t B u, X: C=C, Y=N, Z=C, 64 \%$

\section{Scheme 1.}

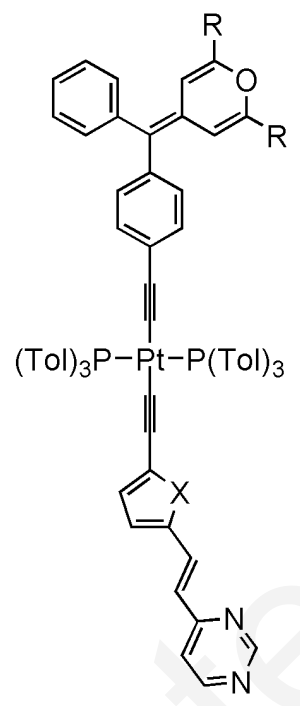

1, $R=P h, X: C=C$

2, $R=P h, X: S$

4, $R=t B u, X: C=C$

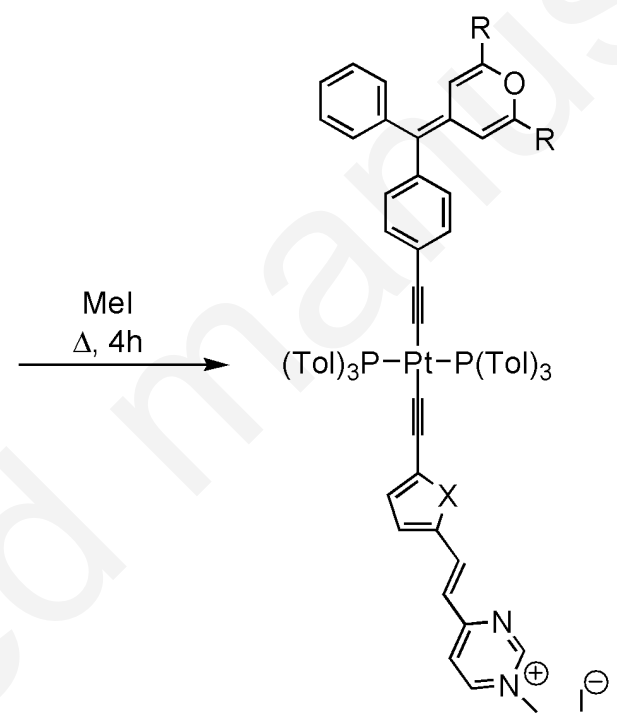

5, $R=P h, X: C=C, 95 \%$

$6, R=P h, X: S, 91 \%$

$7, R=t B u, X: C=C, 96 \%$

\section{Scheme 2.}

In order to study the influence of the platinum on the photophysical and electrochemical properties of complexes 1-7, organic analogues 8-11 were synthesized (Scheme 3). The syntheses of the compounds $\mathbf{8}$ and $\mathbf{9}$ require pyranylidene derivatives $\mathbf{1 2}$ as starting material combined with the bromo derivatives S6-S7, respectively in presence of a catalytic amount of 
bis(triphenylphosphine)palladium(II) chloride and copper(I) iodide. The compounds 8 and 9 are isolated with a rather weak yield (24-26\%). Under $N$-methylation similar to those described for the complexes 5-7, methylated derivatives $\mathbf{1 0}$ and $\mathbf{1 1}$ were obtained in presence of iodomethane under reflux without solvent in good yields.

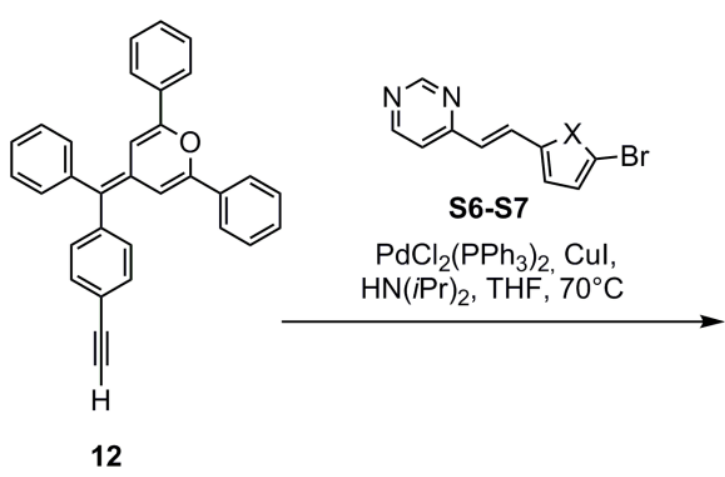

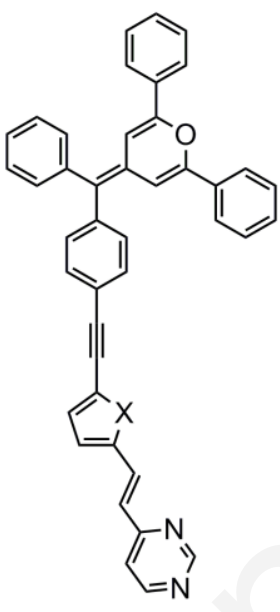

$8, X: C=C, 24 \%$

$9, X: S, 26 \%$

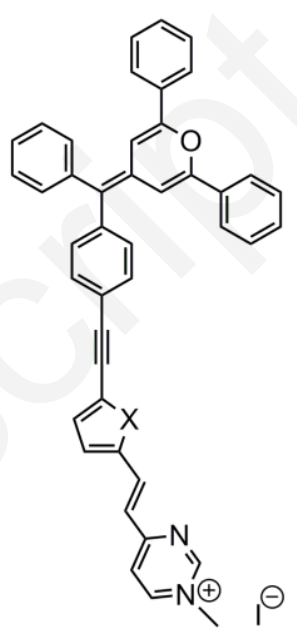

$10, x: C=C, 93 \%$ $11, X: S, 96 \%$

\section{Scheme 3.}

The new compounds were characterized by IR, NMR $\left({ }^{1} \mathrm{H},{ }^{31} \mathrm{P}\right.$, and $\left.{ }^{13} \mathrm{C}\right)$ and high-resolution mass spectrometry (see the ESI). These characterization data fully support the proposed structures.

The IR spectra of the alkynyl complexes 1-7 contain a $v \mathrm{C} \equiv \mathrm{C}$ band at ca. $2100 \mathrm{~cm}^{-1}$ assigned to the metal-bonded alkynyl group, the $\mathrm{vC}=\mathrm{N}$ bands (around $1075 \mathrm{~cm}^{-1}$ and $1175 \mathrm{~cm}^{-1}$ ) and the $\mathrm{v}=\mathrm{C}$ bands (around $1636 \mathrm{~cm}^{-1}$ and $1575 \mathrm{~cm}^{-1}$ ) are characteristics of the vinyldiazine and methylenepyran fragments. ${ }^{13 \mathrm{~h}, 27}$

The ${ }^{1} \mathrm{H}$ NMR spectra of this series of complexes display essentially identical ${ }^{1} \mathrm{H}$ NMR signals for the tri(p-tolyl)phosphines, the pyranylidene ligand, the diazine, the $\pi$-conjugated spacer and the aromatic protons. A similar inductive effect of the platinum coordination has been observed on the characteristic signals. For example for complex $\mathbf{6}$, the hydrogens of the di- 
substituted phenyl $(\delta=6.81$ and $6.20 \mathrm{ppm})$ and the vinylic $\mathrm{H}$ resonance of the methylenepyran core, which appears as two doublets $\left(\delta=6.62\right.$ and $\left.6.59 \mathrm{ppm} ;{ }^{4} J_{\mathrm{H}, \mathrm{H}}=2.0 \mathrm{~Hz}\right)$ are up-field shifted compared to those of the corresponding ligand $\mathbf{8}$.

The $N$-methylated vinyl-pyrimidium fragment on the complexes shows vinylic proton signals as two doublets characteristics of the trans configuration based on the coupling constant (for example $\delta=8.19$ and $6.52 \mathrm{ppm} ;{ }^{3} J_{\mathrm{H}, \mathrm{H}}=14.8 \mathrm{~Hz}$, for $\mathbf{6}$ ) and a singlet for the methyl group (for example $\delta=4.30 \mathrm{ppm}$, for $\mathbf{6}$ ).

Finally, the ${ }^{31} \mathrm{P}$ NMR spectra of all complexes 1-7 exhibit a sharp singlet, characteristic of trans geometries of the phosphine ligands around the platinum (for example $\delta=16.45 \mathrm{ppm}$, ${ }^{1} \mathrm{~J}_{\mathrm{P} t-\mathrm{P}}=2575 \mathrm{~Hz}$, for $\left.\mathbf{6}\right)$. The approximately $3 \mathrm{ppm}$ shift of this singlet upon going from $\mathbf{1 4}$ to $\mathbf{6}$ can be attributed to the electron $\pi$-conjugated bridges

\section{Electrochemical studies}

Cyclic Voltammetry (CV) studies of platinum complexes 1-7 and their organic analogues 811 in dichloromethane were performed in order to account for the effects of various substituting groups on the redox properties. Electrochemical data are gathered in Table 1.

Table 1. $\mathrm{CV}$ data for compounds 1-7 and 8-11 in $\mathrm{CH}_{2} \mathrm{Cl}_{2} / \mathrm{NBu}_{4} \mathrm{PF}_{6} 0.1 \mathrm{M}(E / \mathrm{V}$ vs $\mathrm{Fc}, v=0.1$ $\left.\mathrm{V} \mathrm{s}^{-1}\right)$.

\begin{tabular}{llllllll}
\hline Dye & $E_{\mathrm{pa}}(1)$ & $E_{\mathrm{pa}}(2)$ & $E^{0}(2)$ & $E_{\mathrm{pa}}(3)$ & $E^{0}(3)$ & $E_{\mathrm{pc}}(4)$ & $E_{\mathrm{pc}}(5)$ \\
\hline $\mathbf{1}$ & & 0.19 & 0.14 & 0.41 & 0.36 & & \\
$\mathbf{2}$ & & 0.17 & 0.14 & 0.40 & 0.37 & -0.82 & \\
$\mathbf{3}$ & & 0.17 & 0.12 & 0.40 & 0.35 & & \\
$\mathbf{4}$ & & 0.09 & 0.04 & 0.37 & 0.32 & & \\
$\mathbf{5}$ & -0.12 & 0.17 & 0.13 & 0.41 & 0.37 & & -1.15 \\
$\mathbf{6}$ & -0.13 & 0.19 & 0.14 & 0.43 & 0.38 & & -1.14 \\
$\mathbf{7}$ & -0.08 & 0.17 & 0.10 & 0.41 & 0.36 & & -1.18
\end{tabular}




$\begin{array}{lllll}\mathbf{8} & & 0.29 & 0.61 & \\ \mathbf{9} & & 0.30 & 0.59 & \\ \mathbf{1 0} & -0.12 & 0.29 & 0.61^{\mathrm{a}} & -1.06 \\ \mathbf{1 1} & -0.13 & 0.30 & 0.67^{\mathrm{a}} & -1.03\end{array}$

${ }^{\text {a }}$ Irreversible peak; ${ }^{\mathrm{b}} E^{0}(\mathrm{Fc}+/ \mathrm{Fc})=0.47 \mathrm{~V}$ vs. $\mathrm{SCE}$ in $\mathrm{CH}_{2} \mathrm{Cl}_{2} / \mathrm{NBu}_{4} \mathrm{PF}_{6}$ (measured experimentally) and $E^{0}(\mathrm{SCE})=0.24 \mathrm{~V} v s$. NHE.

All compounds display several redox systems in oxidation, which are mostly reversible. On the contrary, reduction processes, when present, are fully irreversible in the experimental timescale. The comparison between CVs obtained for the compounds led to the following conclusions:

(i) Pt complexes and ligands bearing iodide pyrimidinium substituents display a first oxidation potential at $E_{\mathrm{pa}}(1)$ between $-0.13 \mathrm{~V}$ and $-0.08 \mathrm{~V} v s \mathrm{Fc}$, whereas this peak does not appear for pyrimidine-based compounds (see for example Figure 1A for compared CVs of compounds 1 and 5). Comparison with tetramethylammonium iodide in solution shows that this process corresponds to the reversible iodide oxidation $\left(E_{\mathrm{pa}}=-0.12 \mathrm{~V}\right)$.

(ii) Comparison between complexes and ligands highlights the effect of Pt on the successive oxidation potentials of the pyran moiety at $E^{0}(2)$ and $E^{0}(3)$. Indeed, the potential is shifted by nearly 110-130 mV negative upon Pt incorporation (Figure 1D for compounds 2 and 16). Such effect is ascribed to the increase of electron density on the methylenepyran in presence of the metal, as previously reported..$^{23}$

(iii) The presence of better donating substituents such as $t \mathrm{Bu}$ instead of phenyl groups on the pyran moiety decreases the potential value of $E^{0}(2)$ in a significant manner $\left(\Delta E^{0}(2)=-100\right.$ $\mathrm{mV}$ ), as shown by the comparison between complexes $\mathbf{1}$ and $\mathbf{4}$ (Figure 1C). The second process at $E^{0}(3)$ is also affected but to a lower extent.

(iv) Substitution of a phenyl linker by a thiophenyl one does not modify dramatically the oxidation, or the reduction potentials of the complexes and ligands. 
(v) Reduction of pyrimidium-based Pt complexes and ligands occurs at ca. $E_{\mathrm{pa}}=-1.10 \mathrm{~V}$

vs Fc (Figure 1B for compound 1), this peak is not observed on pyrimidine compounds

(Figure 1B). Such process can be ascribed to the reduction of the pyrimidinium moiety.
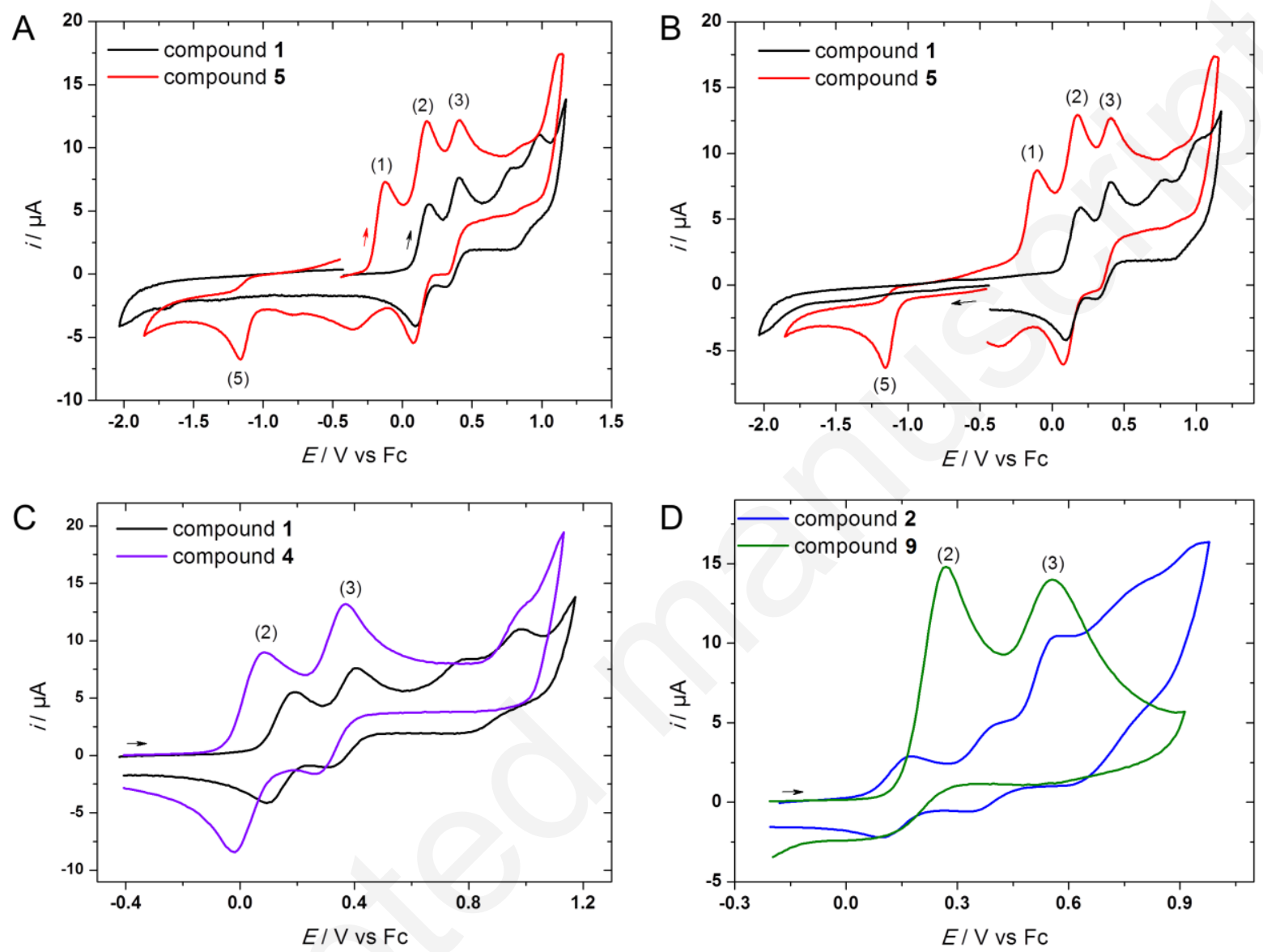

Figure 1. CVs $(v=0.1 \mathrm{~V} / \mathrm{s}, E / \mathrm{V} v s \mathrm{Fc})$ at a $\mathrm{Pt}$ electrode in $\mathrm{CH}_{2} \mathrm{Cl}_{2} / \mathrm{NBu}_{4} \mathrm{PF}_{6} 0.1 \mathrm{M}$ of compounds: A) 1 (black) and 5 (blue) upon scanning in oxidation; B) A) 1 (black) and $\mathbf{5}$ (blue) upon scanning in reduction; C) $\mathbf{1}$ (black) and $\mathbf{4}$ (purple); D) $\mathbf{2}$ (blue) and $\mathbf{9}$ (green).

\section{$U V$-Vis spectroscopy}

The absorption spectra of dyes 1-7 and 8-11 were recorded in chloroform at a concentration of $10^{-4}-10^{-5} \mathrm{M}$ in the $250-800 \mathrm{~nm}$ wavelength range and the results are given in Table 2 . The spectra of compounds 1, 2, 4 and $\mathbf{7}$ are shown in Figure 2a, as examples. For the neutral 
organometallic chromophores 1-4, only one absorption band was observed (398-436 nm). This band is attributed to a transition having some ICT character. When comparing compounds $\mathbf{1}$ and 2, the replacement of the phenylene linker close to the pyrimidine moiety by a thienylene unit results in a significant red shift of the spectrum $\left(\Delta \lambda_{\max }=28 \mathrm{~nm}\right)$, indicating a better ICT. In contrast, replacement of the phenyl substituents by tert-butyl group on the pyranylidene moiety ( $\mathbf{1} v s \mathbf{4})$ lead to a blue shift of the spectrum $\left(\left(\Delta \lambda_{\max }=10 \mathrm{~nm}\right)\right.$. The methylated organometallic dyes 5-7 exhibit two absorption bands: one located in the UVregion (367-396 $\mathrm{nm}$ ) and the second one in the 527-584 $\mathrm{nm}$ attributed to ICT. Once again the thienylene linker leads to a significant bathochromic shift of the ICT absorption band. The ICT absorption bands of the organic derivatives 8-11 are similar (neutral compounds $\mathbf{8}$ and 9) or slightly red-shifted (pyrimidinium derivatives $\mathbf{1 0}$ and 11) to those of their organometallic analogues.

Table 2: Optical data of chromophores 1-7 and 8-11 in $\mathrm{CHCl}_{3}$.

\begin{tabular}{ccccc}
\hline Comp. & $\lambda_{\max }[\mathrm{nm}]$ & $\varepsilon\left[\mathrm{mM}^{-1} \cdot \mathrm{cm}^{-1}\right]$ & $\mu \beta\left[10^{-48} \mathrm{esu}\right]^{\mathrm{a}}$ & $\mu \beta_{0}\left[10^{-48} \mathrm{esu}\right]^{\mathrm{b}}$ \\
\hline $\mathbf{1}$ & 407 & 64 & 260 & 203 \\
$\mathbf{3}$ & 436 & 61 & 170 & 127 \\
$\mathbf{4}$ & 405 & 73 & 160 & 125 \\
$\mathbf{5}$ & 398 & 55 & 390 & 308 \\
$\mathbf{6}$ & $396 / 527$ & $32 / 25$ & 2000 & 1283 \\
$\mathbf{7}$ & $394 / 584$ & $31 / 54$ & 3600 & 2039 \\
$\mathbf{8}$ & $368 / 521$ & $20 / 20$ & 3600 & 2338 \\
$\mathbf{9}$ & $341 / 408$ & $32 / 22$ & 380 & 295 \\
$\mathbf{1 0}$ & 383 & 33 & 220 & 177 \\
& $409 / 540$ & $55 / 9.2$ & 950 & 594 \\
\hline
\end{tabular}




\begin{tabular}{lllll}
\hline 11 & $457 / 579(\mathrm{sh})$ & $29 / 9.0$ & 2300 & 1318
\end{tabular}

${ }^{\mathrm{a}} \mu \beta(2 \omega)$ at $1907 \mathrm{~nm}$. Molecular concentration used for the measurements were in the range $10^{-3}$ to $10^{-2} \mathrm{M} . \mu \beta \pm 10 \%{ }^{\mathrm{b}}$ two level corrected $\beta$ values $\left(\beta_{0}\right) .{ }^{28}$
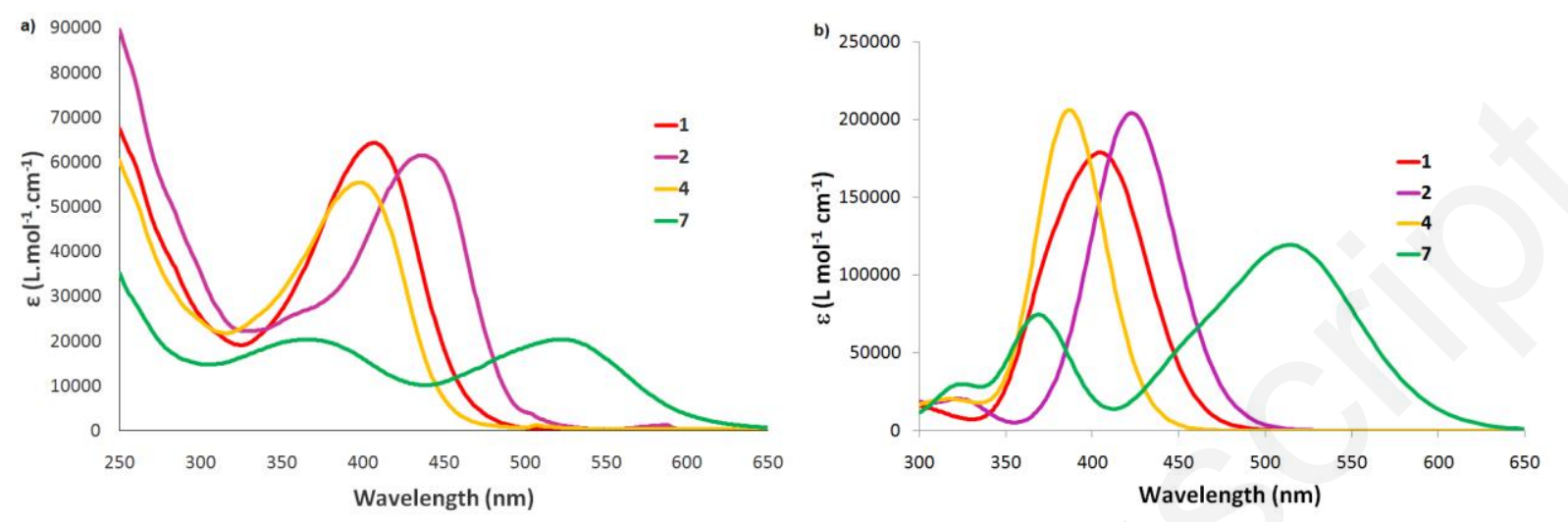

Figure 2: UV-Vis spectra of compounds 1, 2, 4 and 7 in $\mathrm{CHCl}_{3}$.(a) experimental spectra and (b) calculated spectra.

\section{EFISH experiments}

The second-order NLO properties of chromophores 1-7 and 8-11 were investigated by the EFISH technique in $\mathrm{CHCl}_{3}$ solution with a non-resonant incident wavelength of $1907 \mathrm{~nm}$ whose second harmonic $(2 \omega=953 \mathrm{~nm})$ lies in transparent regions of the absorption spectra of the investigated molecules. More information on EFISH apparatus are given elsewhere. ${ }^{29}$ EFISH measurements provide information about the scalar product $\mu \beta(2 \omega)$ of the vector component of the first hyperpolarisability tensor $\beta$ and the dipole moment vector. ${ }^{30}$ This product is derived according to equation 1 considering $\gamma(-2 \omega, \omega, \omega, 0)$, the third-order term, as negligible for the push-pull compounds under consideration, an-approximation commonly used for push-pull organic and organometallic molecules.

$$
\gamma_{\text {EFISH }}=\mu \beta / 5 \mathrm{k} T+\gamma_{0}(-2 \omega, \omega, \omega, 0) \quad \text { Eq. } 1
$$


The zero-frequency $\mu \beta_{0}$ values were calculated by means of the two-level model ${ }^{30}$ using the lowest energy absorption band for each compound. The values obtained are reported in Table 2. All the $\mu \beta$ values are positive, which means that the ground and excited states are polarized in the same direction. As previously observed, methylation of the pyrimidine induces a dramatic increase of the $\mu \beta$ values. ${ }^{11}$ Surprisingly, for the neutral compounds, the replacement of the phenylene linker close to the pyrimidine moiety by a thienylene unit results in a significant decrease of the NLO response ( 2 and $\mathbf{9}$ vs $\mathbf{1}$ and $\mathbf{8}$ respectively). Such phenomenon has already been observed for pyrimidine derivatives. ${ }^{10}$ However, in case of $\mathrm{N}$ methylpyrimidinium chromophores, thienylene derivatives exhibit significantly higher NLO responses (6 and $\mathbf{1 1}$ vs $\mathbf{5}$ and $\mathbf{1 0}$ respectively). The replacement of the phenyl substituents by tert-butyl group on the pyranylidene fragments (4 and 7 vs $\mathbf{1}$ and $\mathbf{5}$ respectively) enhances significantly the NLO response. For neutral chromophores, organometallic complexes exhibit slightly lower $\mu \beta$ values than their all-organic analogues. However for pyrimidinium derivatives, the NLO response is significantly enhanced when a platinum fragment is included in the $\pi$-conjugated core.

\section{Computational investigation}

DFT calculations have been performed on complexes 1-7, as well as their organic relatives 8-11. Their geometries were fully optimized at the PBE0-GD3BJ level, solvent $\left(\mathrm{CHCl}_{3}\right)$ effect corrections included (see computational details). The optimized structures of 1-7 and of 8-11 are shown in Figure 3 and in supporting information. Similarly to the previously reported X-ray structure of a related pyranylidene $\mathrm{Pt}$ complex ${ }^{23}$ all the optimized structures exhibited significant distortion away from planarity. In complex $\mathbf{1}$, for example, the two 6-membered rings participating in the conjugated chain form an angle of $\sim 15^{\circ}$ (pyranylidene side) and $\sim 30^{\circ}$ with the Pt coordination plane, respectively; the angle between these two rings being $\sim 40^{\circ}$. While the conjugated branch on the thiophene-diazine side is 
roughly planar, its counterpart on the pyranylidene side is not, exhibiting a pyran/ $\mathrm{C}_{6}$ ring angle of $\sim 40^{\circ}$. This out-of-plane situation of the pyran moiety is also present in the organic relative $\mathbf{8}$, in which the rest of the conjugated chain remains almost planar (see supporting information). The other computed molecules displayed non-planarity feature similar to those of $\mathbf{1}$ (complexes) or $\mathbf{8}$ (organic relatives). Selected bond distances are given in Table 3. Only minor differences between the $\mathrm{C} \equiv \mathrm{C}$ and $\mathrm{C}=\mathrm{C}$ distances can be noticed in all the compounds. However, it should be noted that the $\mathrm{C} \equiv \mathrm{C}$ bonds of the Pt complexes are $\sim 0.1 \AA$ longer than those of the organic relatives. This can be explained by the difference in nature of the central motives in both series of compounds $(-\mathrm{C} \equiv \mathrm{C}-\mathrm{Pt}-\mathrm{C} \equiv \mathrm{C}-v s$. $-\mathrm{C} \equiv \mathrm{C}-)$. In all compounds, the exocyclic pyranylidene $(\mathrm{C}=\mathrm{C})_{\mathrm{p}}$ bond $\left(\sim\right.$ 1.38-1.39 $\AA$ ) is slightly longer than the $(\mathrm{C}=\mathrm{C})_{\mathrm{d}}$ alkenyl one (1.35-1.38 $\AA$ ), but little dispersion of each of these types of $\mathrm{C}=\mathrm{C}$ bond occurs within the computed series. Thus, from the structural point of view, all the computed compounds exhibit the same trends along the conjugated pathway.

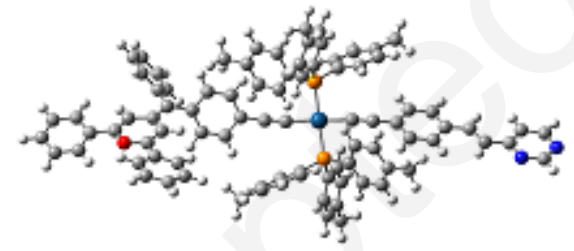

1

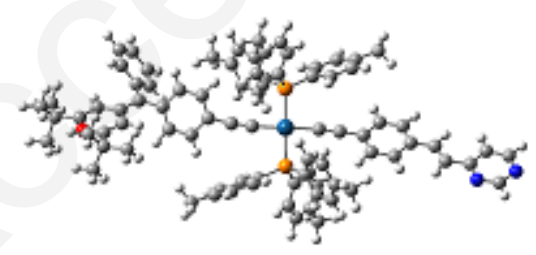

4

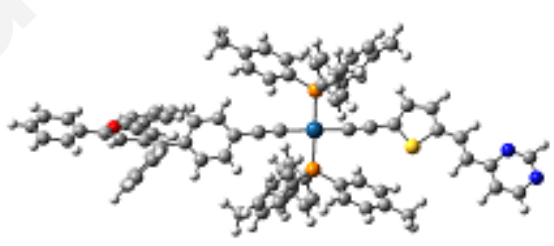

2

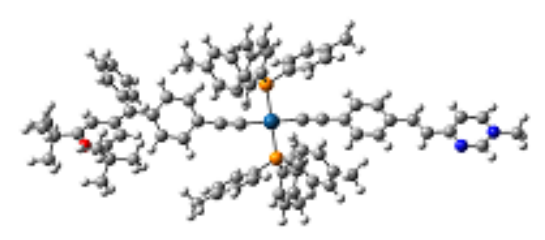

7

Figure 3: DFT-optimized molecular structures of complexes 1, 2, 4 and 7. 
Table 3: Selected bond distances along the conjugated pathway in the DFT-optimized structures of 1-7 and 8-11. The indexes $\mathrm{p}$ and $\mathrm{d}$ label the bonds which are on the pyrynalidene and diazine side, respectively. The reported $\mathrm{C}=\mathrm{C}$ bonds are those not belonging to rings (see Chart 1).

\begin{tabular}{|l|c|c|c|c|c|c|c|c|c|c|c|}
\hline Compound & $\mathbf{1}$ & $\mathbf{2}$ & $\mathbf{3}$ & $\mathbf{4}$ & $\mathbf{5}$ & $\mathbf{6}$ & $\mathbf{7}$ & $\mathbf{8}$ & $\mathbf{9}$ & $\mathbf{1 0}$ & $\mathbf{1 1}$ \\
\hline$(\mathbf{P t}-\mathbf{C})_{\mathbf{p}}$ & 1.976 & 1.977 & 1.976 & 1.977 & 1.975 & 1.975 & 1.976 & & & & \\
\hline$(\mathbf{P t}-\mathbf{C})_{\mathbf{d}}$ & 1.977 & 1.973 & 1.978 & 1.977 & 1.969 & 1.962 & 1.969 & & & & \\
\hline$(\mathbf{C} \equiv \mathbf{C})_{\mathbf{p}}$ & 1.234 & 1.234 & 1.234 & 1.234 & 1.234 & 1.234 & 1.234 & & & & \\
\hline$(\mathbf{C} \equiv \mathbf{C})_{\mathbf{d}}$ & 1.235 & 1.237 & 1.235 & 1.235 & 1.238 & 1.240 & 1.238 & 1.225 & 1.226 & 1.226 & 1.228 \\
\hline$(\mathbf{C}=\mathbf{C})_{\mathbf{p}}$ & 1.382 & 1.382 & 1.382 & 1.380 & 1.382 & 1.382 & 1.380 & 1.383 & 1.384 & 1.386 & 1.387 \\
\hline$(\mathbf{C}=\mathbf{C})_{\mathbf{d}}$ & 1.356 & 1.360 & 1.355 & 1.356 & 1.372 & 1.382 & 1.372 & 1.354 & 1.357 & 1.367 & 1.374 \\
\hline
\end{tabular}

All compounds consistently exhibit similar qualitative features of their electronic structures, as illustrated by the MO diagrams of $\mathbf{1}$ and $\mathbf{8}$ (Figure 4) and of $\mathbf{2}$ and $\mathbf{6}$ (Figure 5). The HOMOs of all compounds are localized on the pyranylidene branch of the conjugated chain, while their LUMOs are localized on the diazine branch. Although less polarized, the HOMO-1 and LUMO+1 are all mainly localized on the diazine and pyranylidene branches, respectively, except for the cations 5-7 for which the LUMO+1 is localized on the diazine ring. Only these four frontier orbitals are involved in the UV-Vis transitions of lowest energy computed by TDDFT (see Table 4). The occupied and vacant Pt(6d) levels of complexes 1-7 are lying farther away from the HOMO-LUMO region and do not significantly participate in the low-energy transitions. The simulated spectra of complexes 1-7 (Figure 2b) are in a fairly good agreement with the experimental ones (Figure 2a). The density-difference plots corresponding to the computed transition of lowest energy are shown in Figure 6. For compounds $\mathbf{1}$ and $\mathbf{3}$, the transition of lowest energy is of major pyranylidene $\rightarrow$ pyranylidene 
$(\mathrm{HOMO} \rightarrow \mathrm{LUMO}+1)$ character. While for compounds $\mathbf{2}$ and $\mathbf{4}$, it occurs mainly on the diazine branch (HOMO-1 $\rightarrow$ LUMO). However, some electron-transfer across the metal center along the conjugated chain can be noticed for 4. This electron transfer is even larger for the cations 5-7, as illustrated by the density difference plots shown in Figure 6 and in supporting information and by the corresponding values of charge and distance transfers ${ }^{31}$ given in Table 4.

Finally, ionization potentials (IE) and electron affinities (EA) of all the investigated complexes were also computed by DFT at the PBE0-GD3 BJ level (see Computational Details and Table S2). Calculations show that oxidation and reduction of any of these compounds always involves the HOMO and LUMO, respectively. The computed IE and EA are in a reasonable agreement with the cyclovoltammetric data.

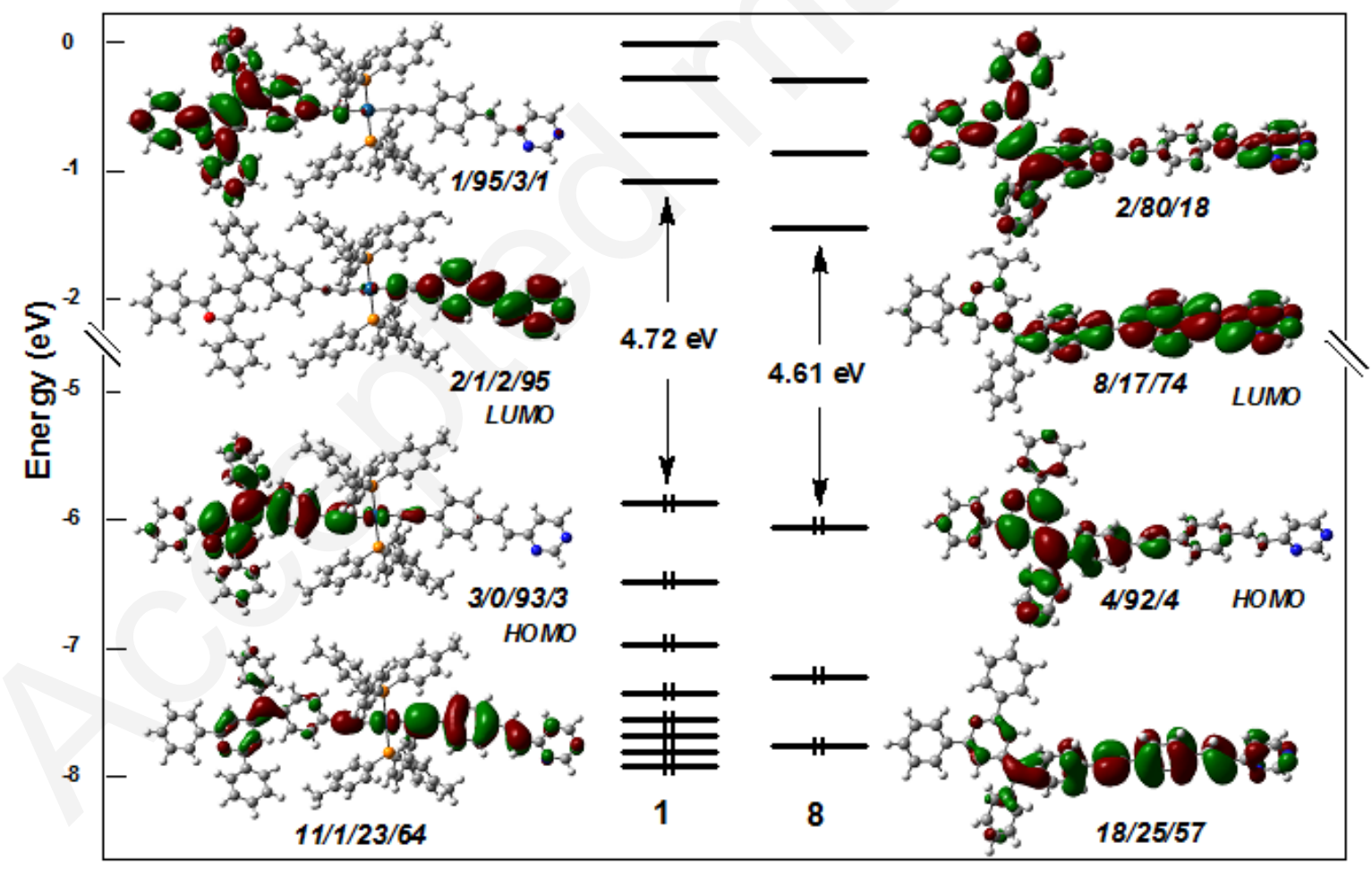


Figure 4: Kohn-Sham MO diagrams of compound $\mathbf{1}$ and $\mathbf{8}$. The numbers correspond to the following fragment localisations (\%): Pt/phosphines/pyranylidene branch/diazine branch and C2/pyranylidene branch/diazine branch for $\mathbf{1}$ and $\mathbf{8}$, respectively.

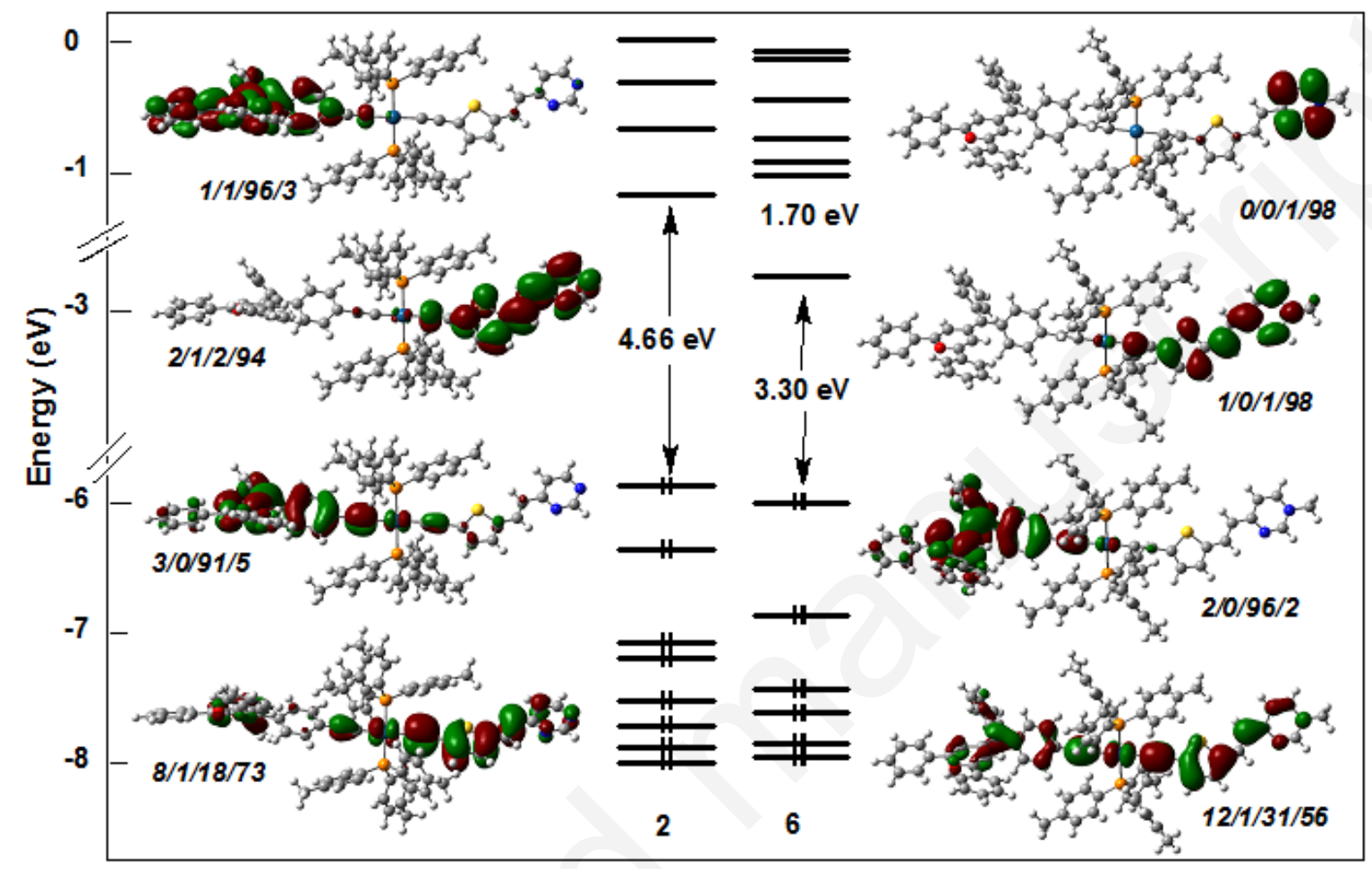

Figure 5: Kohn-Sham MO diagrams of complexes 2 and 6. The numbers correspond to the following fragment localisations (\%): Pt/phosphines/pyranylidene branch/diazine branch.

Table 4: TDDFT-computed UV-vis data for complexes 1-7, ground state $\left(\mu^{\mathrm{GS}}\right)$ and excited state $\left(\mu^{\mathrm{ES}}\right)$ dipole moments. Experimental $\lambda_{\max }$ values are also reported for comparison. Computed oscillator strengths (o.s.) are given in parentheses. $\mathrm{d}^{\mathrm{CT}}$ and $\mathrm{q}^{\mathrm{CT}}$ are the distance and charge transfers associated with the corresponding transitions (see Computational Details).

\begin{tabular}{|c|c|c|c|c|c|c|c|c|}
\hline Compound & $\begin{array}{c}\lambda_{\max }[\mathrm{nm}](\exp . \\
\text { values, see } \\
\text { Table 1) }\end{array}$ & $\begin{array}{c}\lambda \max [\mathrm{nm}] \\
\text { (simulated } \\
\text { spectra, see } \\
\text { Figure C) }\end{array}$ & $\begin{array}{c}\left.\lambda_{\text {calc }}[\mathrm{nm}] \text { and o.s. [u.a. }\right] \\
\text { (major computed } \\
\text { transitions) }\end{array}$ & $\begin{array}{c}\text { Major } \\
\text { contributions }\end{array}$ & $\begin{array}{l}\mathbf{d}^{\mathrm{CT}} \\
{[\AA]}\end{array}$ & $\begin{array}{l}\mathbf{q}^{\mathbf{C T}} \\
{[\mathrm{e}]}\end{array}$ & $\begin{array}{l}\mu^{\mathrm{GS}} \\
{[\mathrm{D}]}\end{array}$ & $\mu^{\mathrm{ES}}[\mathrm{D}]$ \\
\hline
\end{tabular}




\begin{tabular}{|c|c|c|c|c|c|c|c|c|}
\hline $\mathbf{1}$ & 407 & 405 & $377(1.21)$ & $\mathrm{H}-1 \rightarrow \mathrm{L}$ & 3.4 & 0.6 & 5.7 & 16.0 \\
& & & $412(2.08)$ & $\mathrm{H} \rightarrow \mathrm{L}+1$ & 0.6 & 0.5 & 5.7 & 5.2 \\
\hline $\mathbf{2}$ & 436 & 422 & $424(2.64)$ & $\mathrm{H}-1 \rightarrow \mathrm{L}$ & 2.7 & 0.6 & 6.7 & 14.3 \\
\hline $\mathbf{3}$ & 405 & 403 & $377(1.24)$ & $\mathrm{H}-1 \rightarrow \mathrm{L}$ & 3.1 & 0.6 & 3.4 & 12.3 \\
& & & $412(2.07)$ & $\mathrm{H} \rightarrow \mathrm{L}+1$ & 0.7 & 0.5 & 3.4 & 2.1 \\
\hline $\mathbf{4}$ & 398 & 386 & $388(2.77)$ & $\mathrm{H}-1 \rightarrow \mathrm{L}$ & 3.8 & 0.6 & 6.7 & 17.8 \\
\hline $\mathbf{5}$ & 396 & 400 & $399(1.13)$ & $\mathrm{H} \rightarrow \mathrm{L}+2$ & 0.7 & 0.5 & & \\
& 527 & 505 & $508(1.88)$ & $\mathrm{H}-1 \rightarrow \mathrm{L}$ and & 6.5 & 0.9 & & \\
\hline $\mathbf{6}$ & 394 & 398 & $403(1.13)$ & $\mathrm{H} \rightarrow \mathrm{L}+2$ & 4.3 & 1.2 & & \\
& 584 & 538 & $543(2.11)$ & $\mathrm{H}-1 \rightarrow \mathrm{L}$ & 4.7 & 0.7 & \\
\hline $\mathbf{7}$ & 368 & 369 & $369(1.02)$ & $\mathrm{H} \rightarrow \mathrm{L}+3$ & 2.6 & 0.5 & & \\
& 521 & 513 & $519(1.54)$ & $\mathrm{H} \rightarrow \mathrm{L}$ and $\mathrm{H}-$ & 7.3 & 1.0 & \\
& & & & & & & & \\
\end{tabular}

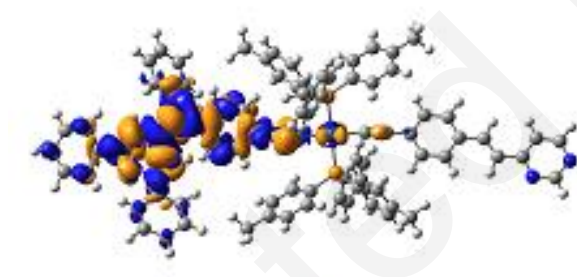

1

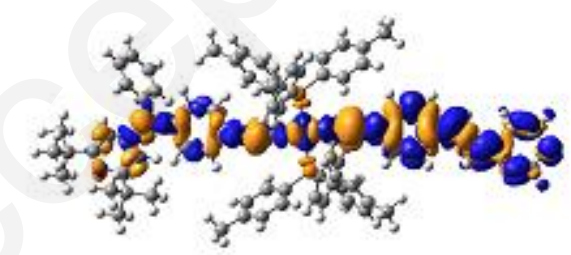

4

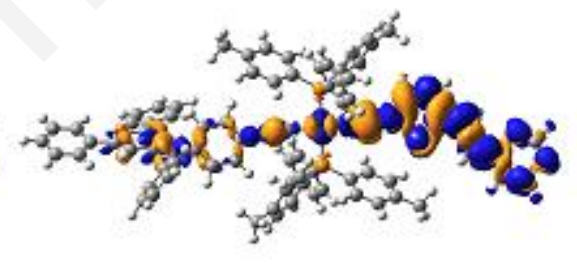

2

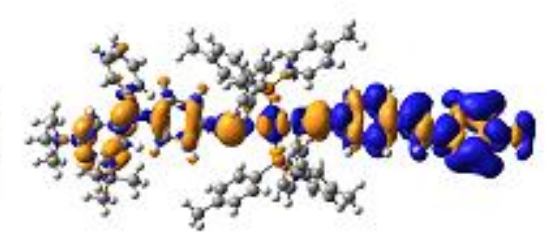

7

Figure 6: Density difference plots associated with the transitions of lowest energy computed for complexes 1, 2, 4 and 7. The blue and yellow colors indicate an increase and decrease of density upon excitation, respectively. 


\section{Conclusion}

In conclusion, our results clearly demonstrate that the incorporation of platinum in the $\pi$ conjugated core of pyranylidene - $N$-methylated pyrimidine ring push-pull chromophores significantly enhances the second-order NLO responses of these chromophores. Remarkably, to the best of our knowledge, complex 7 bearing a tert-butyl group on the pyranylidene flanked on the other side by $N$-methylated vinyl-pyrimidium fragment is characterized by a huge $\mu \beta$ values and among one of the best reported to date for alkynyl metal complexes. In addition, the NLO properties of the push-pull diacetylide platinum-based complexes synthesized can be tailored by varying the nature of the pyranylidene fragments, the type of $\pi$ linkers or by methylation of the pyrimidine fragments, resulting in versatile chromophores that could be useful for second harmonic generation active polymeric films.

\section{Aknowledgements}

We acknowledge Pr. Bertrand Caro for helpful discussion. R. D. thanks the French Ministry of Higher Education and Research for Ph. D. funding. The GENCI-CINES and GENCIIDRISS French national computer centers are acknowledged for computational resources (grant x2016-087367).

${ }^{1}$ Organic Materials for Photonics: Science and Technology; G. Zerbi, Ed.; Elsevier: Amsterdam, 1993.

${ }^{2}$ (a) P. N. Prasad and D. R. Ulrich, Nonlinear optical and electro-active polymers; Plenum Press: New York, 1988. (b) Y. Zhang, J. Ortega, U. Baumeister, C. L. Folcia, G. SanzEnguita, C. Walker, S. Rodriguez-Conde, J. Etxebarria, M. J. O'Callaghan and K. More, J. Am. Chem. Soc., 2012, 134, 16298. 
3 (a) T. Taniuchi, S. Okadaand H. Nakanishi, Appl. Phys. Lett., 2004, 95, 5984; (b) T. Taniuchi, S. Ikeda, S. Okada and H. Nakanishi, Jpn. J. Appl. Phys., 2005, 44, L652; (c) A. Schneider, M. Neis, M. Stillhart, B. Ruiz, R. U. A. Khan and P. Günter, J. Opt. Soc. Am. B, 2006, 23, 1822; (d) A. Schneider, M. Stillhart and P. Günter, Opt. Express, 2006, 14, 5376; (e) Z. Yang, L. Mutter, M. Stillhart, B. Ruiz, S. Aravazhi, M. Jazbinšek, A. Schneider, V. Gramlich and P. Günter, Adv. Funct. Mater., 2007, 17, 2018.

${ }^{4}$ (a) J. Kulhánek, F. Bureš, J. Opršal, W. Kuznik, T. Mikysek and A. Růžička Asian J. Org. Chem., 2013, 2, 422. (b) C. Moreno-Yruela, J. Garín, J. Orduna, S. Franco, E. Quintero, J. T. López Navarrete, B. E. Diosdado, B. Villacampa, J. Casado and R. Andreu, J. Org. Chem., 2015, 80, 12115.

5 (a) F. Bureš, RSC Adv., 2014, 4, 58826; (b) B. J. Coe, Acc. Chem. Res. 2006, 39, 383; (c) I. D. L. Albert, T. J. Marks and M. A. Ratner, J. Am. Chem. Soc. 1997, 119, 6575.

${ }^{6}$ For review see: (a) S. Achelle and N. Plé, Curr. Org. Synth., 2012, 9, 163; (b) S. Achelle and C. Baudequin, Targets Heterocycl. Syst., 2013, 17, 1.

${ }^{7}$ (a) S.-i. Kato, Y. Yamada, H. Hiyoshi, K. Umezu and Y. Nakamura, J. Org. Chem., 2015, 80, 9076; (b) L. Skardziute, J. Dodonova, A. Voitechovicius, J. Jovaisaite, R. Komskis, A. Voitchoviciute, J. Bucevicius, K. Kazlauskas, S. Jursenas and S. Tumkevicius, Dyes Pigm., 2015, 118, 118; (c) V. Schmitt, S. Moschel and H. Detert, Eur. J. Org. Chem., 2013, 5655; (d) N. Hebbar, C. Fiol-Petit, Y. Ramondenc, G. Plé and N. Plé, Tetrahedron, 2011, 67, 2287; (e) C. Denneval, O. Moldovan, C. Baudequin, S. Achelle, P. Baldeck, N. Plé, M. Darabantu and Y. Ramondenc, Eur. J. Org. Chem., 2013, 5591; (f) D. Cvejn, S. Achelle, O. Pytela, J-P. Malval, A. Spangenberg, N. Cabon, F. Bureš and F. Robin-le Guen, Dyes Pigm., 2016, 124, 101. 
${ }^{8}$ (a) Q. Zhang, X-H. Tian, Z.-J. Hu, C. Brommesson, J.-Y. Wu, H.-P. Zhou, J.-X. Yang, Z.-Q. Sun, Y.-P. Tian and K. Uvadal, Dyes Pigm., 2016, 126, 286; (b) J.-P. Malval, S. Achelle, L. Bodiou, A. Spangenberg, L. C. Gomez O. Soppera and F. Robin-le Guen, J. Mater. Chem. C, 2014, 2, 7869; (c) Q. Zhang, L. Li, M. Zhang, Z. Liu, J. Wu, H. Zhou, J. Yang, S. Zhang, Y. Tian, Dalton Trans., 2013, 42, 8848; (d) Z. Liu, P. Shao, Z. Huang, B. Liu, T.Chen and J. Qin, Chem. Commun., 2008, 2260; (e) L. Li, Y.-P. Tian, J.-X. Yang, P.-P.Sun, J.-Y. Wu, H.P. Zhou, S.-Y. Zhang, B.-K. Jin, X.-J. Xing, C.-K. Wang, M. Li, G.-H. Cheng, H.-H. Tang, W.-H. Huang, X.-T. Tao and M.-H. Jiang, Chem. Asian J., 2009, 4, 668.

${ }^{9}$ (a) S. Achelle, A. Barsella, C. Baudequin, B. Caro and F. Robin-le Guen, J. Org. Chem. 2012, 74, 3711; (b) F. Castet, A. Pic and B. Champagne, Dyes Pigm., 2014, 110, 256.

${ }^{10}$ S. Achelle, A. Barsella, B. Caro and F. Robin-le Guen, RSC Adv., 2015, 5, 39218.

${ }^{11}$ S. Achelle, S. Kahlal, A. Barsella, J.-Y. Saillard, X. Che, F. Bureš, B. Caro and F. Robin-le Guen Dyes Pigm., 2015, 113, 562.

12 (a) S. R. Marder, D. N. Beratan and L.-T. Cheng, Science 1991, 252, 103; (b) S. R. Marder, L.-T. Cheg, B. G. Tiemann, A. C. Friedli, M. Blanchard-Desce J. W. Perry, J. Skindhøj, Science, 1994, 263, 511.

${ }^{13}$ (a) P. Solanke, S. Achelle, N. Cabon O. Pytela, A. Barsella, B. Caro, F. Robin-le Guen, J. Podlesný, M. Klikar and F. Bureš,. Dyes Pigm., 2016, 134, 129; (b) A. B. Marco, N. Martínez de Baroja, S. Franco, J. Garín, J. Orduna, B. Villacampa, A. Revuelto and R. Andreu, Chem.Asian J., 2015, 10, 188; (c) A. B. Marco, P. Mayorga Burrezo, L. Mosteo, S. Franco, J. Garín, J. Orduna, B. E. Diosdado, B. Villacampa, J. T. López Navarrete, T. Casado and R. Andreu, RSC Adv., 2015, 5, 231; (d) S. Gauthier, N. Vologdin, S. Achelle, A. Barsella, B. Caro and F. Robin-le Guen, Tetrahedron, 2013, 69, 8392; (e) A. B. Marco, R. Andreu, S. Franco, J. Garín, J. Orduna, B. Villacampa, B. E. Diosdado, J. T. López Navarrete and T. Casado, Org. 
Biomol. Chem., 2013, 11, 6338. (f) R. Andreu, E. Galán, J. Orduna, B. Villacampa, R. Alicante, J. T. López Navarrete, J. Casado and J. Garín, Chem. Eur. J., 2011, 17, 826; (g) R. Andreu, L. Carrasquer, S. Franco, J. Garín, J. Orduna, N. Martínez de Baroja, R. Alicante, B. Villacampa and M. Allain, J. Org. Chem., 2009, 74, 6647; (h) N. Faux, F. Robin-le Guen, P. le Poul, B. Caro, K. Nakatani, E. Ishow and S. Golhen, Eur. J. Inorg. Chem., 2006, 3489.

${ }^{14}$ (a) J.-M. Andres-Castan, S. Franco, B. Villacampa, J. Orduna and R. Pérez-Tejada, RSC Adv., 2015, 5, 106706; (b) R. Pérez Tejada, L. Pellejà, E. Palomares, S. Franco, J. Orduna, J. Garín and R. Andreu, Org. Electron., 2014, 15, 3237; (c) S. Franco, J. Garín, N. Martínez de Baroja, R. Pérez-Tejada, J. Orduna, Y. Yu and M. Lira-Cantu, Org. Lett., 2012, 14, 752; (d) A. Bolag, J. Nishida, K. Hara and Y.Yamashita, Org. Electron., 2012, 13, 425.

${ }^{15}$ S. Achelle, J.-P. Malval, S. Aloïse, A. Barsella, A. Spangenberg, L. Mager, H. Akdas-Kilig, J.-L. Filaut, B. Caro and F. Robin-le Guen, ChemPhysChem, 2013, 14, 2725.

16 (a) S. Achelle, S. Kahlal, J.-Y. Saillard, N. Cabon, B. Caro and F. Robin-le Guen, Tetrahedron, 2014, 70, 2804; b) F. Ba, N. Cabon, P. le Poul, S. Kahlal, J.-Y. Saillard, N. le Poul, S. Gohlen, B. Caro and F. Robin-le Guen, New J. Chem., 2013, 37, 2066. c) F. Ba, N. Cabon, F. Robin-le Guen, P. le Poul, N. le Poul, Y. le Mest, S. Gohlen and B. Caro, Organometallics, 2008, 27, 6396.

17 (a) I. R. Whittall, M. G. Humphrey, M. Samoc, J. Swiatkiewicz and B. Luther-Davies, Organometallics, 1995, 14, 5493; (b) M. P. Cifuentes and M. G. Humphrey, J. Organomet. Chem., 2004, 689, 3968; (c) C. E. Powell and M. G. Humphrey, Coord. Chem. Rev., 2004, 248, 725; (d) G.-J. Zhou and W.-Y. Wong, Chem. Soc. Rev., 2011, 40, 2541; (e) G.-J. Zhou, W.-Y. Wong, Z. Lin and C. Ye, Angew. Chem. Int. Ed., 2006, 45, 6189; (f) G.-J. Zhou, W.-Y. Wong, C. Ye and Z. Lin, Adv. Funct. Mater., 2007, 17, 963. 
18 (a) A. Colombo, F. Nisic, C. Dragonetti, D. Marinotto, I. P. Oliveri, S. Righetto, M. G. Lobello and F. De Angelis, Chem. Commun. 2014, 50, 7986; (b) A. Colombo, C. Dragonetti, D. Marinotto, S. Righetto, G. Griffini, S. Turri, H. Akdas-Kilig, J.-L. Fillaut, A. Amar, A. Boucekkine, and C. Katan, Dalton Trans. 2016, 45, 11052; (c) J. Boixel, V. Guerchais, H. Le Bozec, D. Jacquemin, A. Amar, A. Boucekkine, A. Colombo, C. Dragonetti, D. Mariotto, D. Roberto, S. Righetto and R. De Angelis, J. Am. Chem. Soc. 2014, 136, 5367.

${ }^{19}$ (a) F. Malvolti, C. Rouxel, A. Triadon, G. Grelaud, N. Richy, O. Mongin, M. BlanchardDesce, L. Toupet, F. I. Abdul Razak, R. Stranger, M. Samoc, X. Yang, G. Wang, A. Barlow, M. P. Cifuentes, M. G. Humphrey and F. Paul, Organometallics, 2015, 34, 5418; (b) M. Samoc, G. T. Dalton, J. A. Gladysz, Q. Zheng, Y. Velkov, H. Ågren, P. Norman and M. G. Humphrey, Inorg Chem., 2008, 47, 9946. (c) S. Goswami, R. W. Winkel and K. S. Schanze, Inorg. Chem. 2015, 54, 10007; (d) F. Nisic, A. Colombo, C. Dragonetti, E. Garoni, D. Marinotto, S. Righetto, F. De Angelis, M. G. Lobello, P. Salvatori, P. Biagini and F. Melchiorre, Organometallics, 2015, 34, 94-104. (e) E. Rossi, A. Colombo, C. Dragonetti, S. Righetto, D. Roberto, R. Ugo, A. Valore, J. A. Williams, M. G. Lobello, F. De Angelis, S. Fantacci, I. Ledoux-Rak, A. Singh and J. Zyss Chem. Eur. J. 2013, 19, 9875.

${ }^{20}$ (a) W. Wang and H.-B. Yang, Chem. Commun., 2014, 50, 5171; (b) A. Chowdhury, P. Howlader and P. S. Mukherjee, Chem. Eur. J., 2016, 22, 1424.

21 (a) C. Liao, A. H. Shelton, K.-Y. Kim and K. S. Schanze, ACS Appl. Mater. Interfaces, 2011, 3, 3225; (b) D. Wang, L.-Y. Zou, S. Huang, J.-K. Feng and A.-M. Ren, Dyes Pigm., 2014, 105, 75; (c) A. Rebane, M. Drobizhev, N. S. Makarov, G. Wicks, P. Wnuk, Y. Stepanenko, J. E. Haley, D. M. Krein, J. L. Fore, A. R. Burke, J. E. Slagle, D. G. McLean, and T. M. Cooper, J. Phys. Chem. A, 2014, 118, 3749. 
22 (a) P. Nguyen, G. Lesley, T. P. Marder, I. Ledoux and J. Zyss, Chem. Mater., 1997, 9, 406; (b) R. D'Amato, A. Furlani, M. Colapietro, G. Partalone, M. Casalboni, M. Falconieri and M. V. Russo, J. Organomet. Chem., 2001, 627, 13; (c) P. A. Scattergood, M. Delor, I. V. Sazanovich, O. V. Bouganov, S. A. Tikhomirov, A. S. Stasheuski, A. W. Parker, G. M. Greetham, M. Towrie, E. S. Davies, A. J. H. M. Meijerand and J. A. Weinstein, Dalton Trans., 2014, 43, 17677; (d) Á. J. Jiménez, M. Sekita, E. Caballero, M. L. Marcos, M. S. Rodríguez-Morgade, D. M. Guldi and T. Torres, Chem. Eur. J., 2013, 19, 14506.

${ }^{23}$ S. Gauthier; B. Caro, F. Robin-le Guen, N. Bhuvanesh, J. A. Gladysz, L. Wojcik, N. le Poul, A. Planchat, Y. Pellegrin, E. Blart, D. Jacquemin and F. Odobel, Dalton Trans., 2014, 43, 11233.

${ }^{24}$ (a) W. Wu, J. Zhang,H. Yang, B. Jin, Y. Hu, J. Hua, C. Jing, Y. Long and H. Tian, J. Mater. Chem., 2012, 22, 5382-5389; (b) W. Wu, J. Zhao, J. Sun, L. Huang and X. Yi, J. Mater. Chem. C, 2013, 1, 705.

${ }^{25}$ E. Matern, J. Pikies and G. Z. Fritz, Anorg. Allg. Chem., 2000, 626, 2136.

${ }^{26}$ A.I. Aranda S. Achelle, F. Hammerer, F. Mahuteau-Betzer and M.P. Teulade-Fichou, Dyes Pigm., 2012, 95, 400.

${ }^{27}$ J. D. Hepworth, C. D. Gabbutt, B. M. Heron, in ComprehensiveHeterocyclic Chemistry, 2nd ed. (Ed.: A. McKillop), Elsevier, Oxford, 1996, vol. 5, p. 301

28 (a) J. L Oudar and D. S. Chemla, J. Chem. Phys., 1977, 66, 2664; (b) D. R. Kamis, M. A. Ratner and T. J. Marks, Chem. Rev., 1994, 94, 195.

${ }^{29}$ G. Ulrich, A. Barsella, A. Boeglin, S. L. Niu and R. Ziessel, ChemPhysChem, 2014, 15, 2693.

${ }^{30}$ L. T. Cheng, W Tam, S. H. Stevenson, G. R. Meredith, G. Rikken and S. R. Marder, J. Phys. Chem., 1991, 95, 10631. 
31 (a) T. Le Bahers, C. Adamo and I. Ciofini, J. Chem. Theory Comput., 2011, 7, 2498; (b) I. Ciofini, T. Le Bahers, C. Adamo, F. Odobel and D. Jacquemin, J. Phys. Chem. C, 2012, 116, 11946; (c) D. Jacquemin, T. L. Bahers, C. Adamo and I. Ciofini, Phys. Chem. Chem. Phys., 2012, 14, 5383. 